\title{
Dor crônica: objeto insubordinado
}

\section{Chronic pain: an insubordinate object}

\section{Mônica Angelim Gomes de Lima}

Faculdade de Medicina / Universidade Federal da Bahia

Av. Reitor Miguel Calmon, s.n. 40110-100 Salvador - BA - Brasil angelim@ufba.br

\section{Leny Trad}

Instituto de Saúde Coletiva / Universidade Federal da Bahia Rua Padre Feijó, 29 40110-170 Salvador - BA - Brasil trad@ufba.br

LIMA, Mônica Angelim Gomes de; TRAD, Leny Alves Bomfim. Dor crônica: objeto insubordinado. História, Ciências, Saúde - Manguinhos, Rio de Janeiro, v.15, n.1, p.117-133, jan.-mar. 2008.

Discutem-se as lacunas no estudo da dor crônica, bem como as possíveis aberturas e as novas possibilidades no cuidado à saúde, com base no reposicionamento e na interação dos agentes envolvidos. Procura organizar uma moldura teórico-metodológica que permita examinar as soluções construídas no interior da biomedicina para incluir a dor crônica como objeto da atenção médica. Tem caráter exploratório e organiza uma leitura epistemológica sobre a constituição da dor crônica como objeto médico, pontuando mudanças e permanências no interior da biomedicina. Organiza uma proposta teórico-metodológica voltada à compreensão da produção de sentidos da dor por parte de profissionais de saúde e sofredores.

Palavras-chave: dor crônica; biomedicina; clínica de dor.

LIMA, Mônica Angelim Gomes de; TRAD, Leny Alves Bomfim. Chronic pain: an insubordinate object. História, Ciências, Saúde - Manguinhos, Rio de Janeiro, v.15, n.1, p.117-133, Jan.-Mar. 2008.

Based on reflections on the complexity of chronic pain and its impact on the main constituent elements of biomedicine, the article examines the gaps this phenomenon has revealed both in the production of knowledge and in clinical practice. It discusses new possibilities in health care based on the repositioning of agents and their interactions. This exploratory article presents an epistemological reading of the construction of chronic pain as a medical object, highlighting changes and constancies within biomedicine. It also presents a theoretical and methodological proposal focused on understanding the production of meanings of 'pain' among doctors, healthcare providers, and sufferers.

Keywords: chronic pain; biomedicine; pain clinics. 
A dor crônica é um objeto complexo que escapa ao paradigma biomédico. Pode ser pensada como uma anomalia na perspectiva kuhniana. ${ }^{1}$ No amplo debate que suscita dentro e fora da biomedicina, expõe brechas do paradigma biomédico por ser uma experiência privada, situada na interação corpo-mente, tornando o sofredor incapaz de ter sua experiência reconhecível. A constituição da dor crônica como objeto médico pela medicina contemporânea revela uma construção histórica e epistemológica, estimulando a reflexão sobre a biomedicina como racionalidade médica e sobre as aberturas operadas na prática clínica por causa da práxis dos agentes envolvidos.

A presença da dor crônica como problema de saúde pública tem sido referida em estudos atuais, que apontam prevalências entre $7 \%$ e $46 \%$ na população geral e pouco menos de $30 \%$ dos pacientes atendidos em serviços de atenção primária à saúde (Eliot et al., Oct. 1999; Blyth et al., 2001; Hasselstrom, Liu-Palmgrenb, Rasjo-Wraakr, Oct. 2002; Teixeira et al., 2003). No Brasil, foi realizado um estudo na cidade de Londrina (PR) envolvendo 1871 moradores. Das 915 crianças com idade entre 7 e 14 anos, 28,78\% tiveram diagnóstico de dor crônica e entre os 515 adultos entrevistados, $61,38 \%$ enquadravam-se nos critérios desse diagnóstico, com perda de desempenho mas sem causar necessariamente ausência no trabalho. Entre 451 idosos (entre 60 e 85 anos), 51,4\% tinham dor crônica (Pimenta et al., 2005).

O fato é acompanhado pela crescente demanda por serviços de saúde e pela concentração de recursos tecnológicos para a abordagem da dor e da incapacidade e sofrimento decorrentes dela. O tratamento da dor crônica tem se caracterizado pelo alto custo; mais recentemente, questiona-se sua efetividade, assim como a proposição de ações públicas da atenção à saúde específicas para esse caso (Berker et al., 2000; Cohen, Campbell, 1996). Para o cuidado da dor crônica têm sido constituídas as chamadas clínicas de dor, organizadas no Brasil desde o início da década de 1980 e, no mundo, a partir dos anos 1970. Em linhas gerais, são centros multiprofissionais, situados principalmente em escolas médicas, que agregam especialistas em terapêuticas convencionais (biomedicina, fisioterapia, psicologia e terapia ocupacional) e algumas não convencionais, mais freqüentemente a acupuntura e a hipnose ${ }^{2}$ (Castro, 1999).

Deve-se analisar a compreensão atual da dor crônica tendo em vista as mudanças e adaptações em várias áreas no interior da biomedicina. As doenças crônicas, de modo geral, têm impulsionado mudanças que afetam principalmente a relação do médico com os demais profissionais de saúde e com o paciente. A maior atenção à experiência do doente e a sua autobiografia, o modelo temporal da enfermidade, orientando uma abordagem da saúde baseada na totalidade do ciclo da vida, a multicausalidade e principalmente as tentativas de estabelecer parcerias com o paciente na condução do processo terapêutico são fatos que podem ser tomados como indicadores de mudanças significativas da biomedicina (Lock, Gordon, 1988; Baszanger, 1989; Bendelow, Williams, 1995).

A biomedicina como racionalidade médica ${ }^{3}$, conforme proposto por Madel Luz (1993; 1996), admite flexibilidades e modificações em seu interior, mantendo contudo alguns elementos que a podem definir como um 'tipo ideal' na perspectiva weberiana, como um modelo tendencial histórico. Segundo Kenneth Camargo Junior (2003), essa racionalidade pode ser delineada com base em três proposições: (1) seu caráter generalizante, pela produção de discursos com validade universal, não se ocupando de casos individualizados; (2) seu caráter mecanicista, que aborda o universo à imagem de uma máquina "subordinada a princípios de 
causalidade linear traduzíveis em mecanismos"; e (3) seu caráter analítico, baseado numa abordagem teórica e experimental voltada à "elucidação das leis gerais do funcionamento da máquina universal", tendo como pressuposto que o funcionamento do todo é necessariamente dado pela soma das partes (p.107).

Este artigo trata da biomedicina e toma por objeto a dor crônica. Procura organizar uma moldura teórico-metodológica que permita examinar as soluções construídas no interior da biomedicina para incluir a dor crônica como objeto da atenção médica. Pretende revelar brechas e apontar possíveis aberturas, discutir mudanças e permanências, com base na reflexão sobre os pressupostos da biomedicina mais requeridos para a compreensão da dor crônica, ao lado de valores éticos e morais que são reafirmados na prática. O naturalismo e o dualismo corpomente figuram entre os pressupostos que podem ser questionados e/ou fortalecidos nesse processo.

\section{A dor crônica para a biomedicina: mudanças e permanências}

Na biomedicina, mais especificamente no campo da neurociência, tem-se conformado, a partir dos anos 1960, uma forte tendência a considerar a dor crônica como uma entidade mórbida, uma doença, com tentativas de explicação baseadas na neurofisiologia e caracterização da sua sintomatologia, com o comprometimento de várias dimensões do ser humano. A dor é atualmente definida como "uma experiência sensorial e emocional desagradável relacionada com o dano real ou potencial de algum tecido ou que se descreve em termos de tal dano" (Pimenta, 1999, p.11). Tal conceito reflete mudanças na concepção da dor, admitindo-se desde o 'dano real' (no corpo), o 'potencial' (a ameaça), ou algo 'que se descreve em termos de tal dano', aquele que mesmo não estando no corpo, não sendo 'visível', é percebido e descrito como estando nele pelo doente. Essa amplitude conceitual absorve o visível e o invisível impostos pela dor, notadamente a dor crônica. A dor está no corpo, na mente, na história de vida, no cotidiano, no mundo da vida, ou seja, é multidimensional.

A dor aguda tem função de alerta, segue-se a uma lesão tecidual e geralmente desaparece após resolução do processo patológico. É bem delineada temporalmente, apresenta alterações neurovegetativas sistêmicas, tem fisiopatologia bem compreendida, seu diagnóstico etiológico não é difícil, suas intensidade e localização têm boa correspondência com o local e a dimensão da lesão tecidual, e o controle é adequado graças aos recursos atuais da biomedicina. Até aqui essa descrição corresponde ao que Jacobsen Teixeira et al. (2003, p.157) denominam dor fisiológica. No entanto, ao fugir desse padrão e tornar-se crônica, os mecanismos neurofisiológicos envolvidos modificam-se e a dor ganha a qualificação 'patológica'. O processo de transformação de uma a outra não é conhecido, embora o meio médico tenda a considerar que o tratamento inadequado da dor aguda pode levar à sua cronificação.

A mudança na compreensão da dor inicia-se na proposição conhecida por Teoria de Comporta, publicada em 1965. Seus autores, Melzack e Wall (1965), tentam explicar o sistema nervoso como um sistema interativo de comunicação multidirecional, capaz de receber, organizar, modular e responder, em diversos níveis, aos estímulos dolorosos e não dolorosos, a partir de um processo de colisão de potenciais nervosos dos distintos receptores, presentes na substância gelatinosa do corno posterior da medula espinhal (CPME) $)^{4}($ Melzack, Wall, 1965; 
Melzack, Wall, 1982; Teixeira, 1999). A teoria parte da crítica às teorias anteriores - Teoria da Especificidade e Teoria do Padrão -, que apresentariam lacunas para explicar certas evidências clínicas como a causalgia ${ }^{5}$, a dor fantasma e as neuralgias periféricas. No entanto não oferece uma definição específica para a dor crônica.

O tempo de duração é o elemento de diferenciação entre a dor aguda e a crônica. Apesar de controversos, os limites temporais de dor definidos pelo Comitê de Taxonomia da Sociedade Internacional para o Estudo da Dor (Iasp) são: duração menor que um mês; de um a seis meses; e mais de seis meses (Teixeira et al., 2003). A dor crônica é principalmente reconhecida quando sua duração ultrapassa seis meses. Outros critérios são incluídos, baseados na área de atuação. A dor oncológica, por exemplo, é considerada crônica desde seu início. Alguns autores valorizam mais o critério clínico, e consideram dor crônica aquela que persiste além do tempo razoável para a cura da lesão, ou está associada a processos patológicos que causam dor contínua, ou são recorrentes durante meses ou anos (Teixeira, 1999). Essa compreensão ressalta a nãocorrelação entre dor, lesão e permanência da dor além do esperado, ou seja, depois de concluído o processo de cicatrização da lesão tecidual.

Apesar das críticas recebidas, a Teoria de Comporta ofereceu indubitavelmente um novo leque de questões e possibilidades à biomedicina e permitiu a integração de novas abordagens terapêuticas, que valorizam os mecanismos modulatórios da dor, a interpretação clínica da sintomatologia dolorosa e o comportamento doloroso mais do que a nocicepção propriamente dita. Práticas do campo da medicina física como cinesioterapia, acupuntura, práticas corporais ativas e passivas, psicologia cognitivo-comportamental e hipnose foram fortemente associadas ao 'arsenal terapêutico da dor', em substituição ou priorização à interrupção cirúrgica da transmissão nervosa (Teixeira et al., 2003; Melzack, Wall, 1982).

Esse novo entendimento da dor descortina importantes questões para a biomedicina, pois atinge frontalmente cânones da racionalidade médica, quais sejam: a constituição do 'olhar médico' (Foucault, 1977) e a diferenciação entre 'normal' e 'patológico' (Canguilhem, 1982). De certo modo, dispara um processo que, por um lado, tende a dar lugar à dor crônica dentro das fronteiras da biomedicina, mas, por outro, desarma um 'olhar' partilhado pelo médico, demais profissionais de saúde e o próprio doente na leitura do discurso médico.

De acordo com Arthur Kleinman et al. (1994), a dor crônica representa um caso especial na nosologia biomédica atual, pois é diferente das desordens biomédicas crônicas de um modo geral, como diabetes ou hipertensão, e das doenças psiquiátricas reconhecidas, como a depressão. A dor crônica é usada como uma categoria não-oficial, isto é, anômala, parcialmente legitimada como doença. Na ausência de mecanismos fisiológicos conhecidos, a atenção tem se voltado para determinantes psicológicos e sociais da dor.

\section{Dor crônica: uma ontologia fragilizada}

Michel Foucault (1977), em sua arqueologia do discurso médico, apresenta o evento do nascimento da clínica como pretexto para propor uma 'arqueologia do olhar' voltada para o contexto de mudanças do pensamento ocidental, no processo de constituição da ciência moderna. A inauguração da medicina moderna se dá exatamente pela conformação de um novo olhar sobre o corpo e pela possibilidade de integração deste a uma linguagem. 
O sintoma como 'ato de descrição' assume o lugar do signo, mas tal condição só é possível "sob um olhar sensível à diferença, à simultaneidade ou à sucessão e à freqüência" (Machado, 1981, p.103) . A perspectiva do olhar como ato de descrição implica a relação entre o que se vê e o que se fala, a partir de um sujeito capaz de reconhecer os signos como uma linguagem, permitindo ao olhar clínico "essa paradoxal propriedade de ouvir uma linguagem no momento em que percebe um espetáculo" (Foucault, 1977, p.108). Isso permite pensar a 'doença' como um objeto, como entidade ontológica na medicina moderna que demanda do médico o seu reconhecimento por meio de signos, tornados 'visíveis' graças a um olhar que ganha densidade com a exploração do corpo em camadas cada vez mais profundas, e do reconhecimento das relações entre tecidos e estruturas por uma tékhne pautada na triangulação sensorial visãotato-audição (Foucault, 1977; Machado, 1981).

Essa visibilidade estará orientada principalmente pela noção de lesão, principal referência para a materialização da doença, embora se possam observar mudanças na noção, passando de um nível macro-estrutural, que inclui tecidos e órgãos, em direção ao micro-ambiente celular, ou ainda ao ultramicro-ambiente celular das estruturas protéicas das membranas celulares, da bioquímica, dos canais iônicos, da organização gênica (Camargo Junior, 2003).

Outro elemento central dessa medicina é a idéia de normalidade e sua oposição, o patológico. Essa divisão, conforme crítica de Canguilhem (1982), possui limite tênue, só possível de ser percebido na observação sucessiva de um único indivíduo ao longo do tempo, quanto à variação da capacidade em alargar ou estreitar suas possibilidades de adaptação às variações internas e externas, promovendo a emergência de uma nova norma. Na dor crônica, tanto a sua visibilidade ao olhar médico como a sua inclusão em parâmetros capazes de discernir entre o normal e o patológico estão comprometidos. Esses aspectos impactam tanto a prática clínica como a produção de conhecimento.

Uma frase repetida na literatura especializada e confirmada no cotidiano clínico é: "Não há correlação entre dor e lesão no caso da dor crônica". A neurofisiologia direciona, portanto, a espacialização da dor crônica e sua causalidade para o domínio da ultraneuro-fisiologia, nos canais iônicos, mais especificamente nos canais de sódio. No entanto nessa dimensão o grau de incerteza aumenta, a busca da localização esbarra na ausência mesmo da substância, pois a dinâmica está em primeiro plano em relação ao lócus. Para M.S. Gold, neurofisiologista que estuda os canais iônicos presentes na membrana celular do tecido nervoso, os canais de sódio, elemento fundamental para o entendimento da transmissão nervosa, não só têm várias subunidades como estas apresentam dinâmica própria, modificando-se inúmeras vezes pela sensibilidade química e elétrica. Reconhecer as alterações aí presentes implica orientar o olhar para a dinâmica mais do que para o ponto.

Com tal grau de imaterialidade, o normal e o patológico perdem seu substrato, anulando a eficácia dos instrumentos de medida, escalas, termômetros, relógios, indicadores bioquímicos que "produzem números sobre os quais erigem-se, materializam-se, policiam-se as fronteiras do normal e do patológico" (Borck, Hess, Schmidgen, 2001). Trata-se portanto de uma 'ontologia fragilizada'. Mesmo sendo assumida como doença, a dor crônica mantém-se invisível ao olhar médico, mantém-se à margem da subcultura médica, com conseqüências ainda não superadas para médicos e doentes (Rhodes et al., 1999). Pode-se pensar que a dor crônica, mesmo com as mudanças de status pontuadas, está a meio caminho. Aceita como objeto da biomedicina, não 
é tratada apenas como uma enfermidade (illness) percebida pelo sofredor; é remetida à condição de doença (disease), portanto objeto médico, mas não oferece sinais objetivos que possam de fato trazê-la à visibilidade médica.

Nesse sentido, a dor crônica constitui-se como um 'semblante', como nomeia Clavreul (1983), quando se refere ao objeto da clínica, oferecendo 'fatos' organizados pelo recurso da semelhança. Tal recurso não é estranho à medicina, que teve e tem que constituir semblantes para delinear síndromes e doenças com base no reconhecimento de semelhanças entre doentes. A constituição de uma 'entidade patológica' em si resulta do reconhecimento das semelhanças, da freqüência e da probabilidade (Foucault, 1977; Machado, 1981, Clavreul, 1983). O risco a que nos alerta Clavreul (1983) é a tendência em constituir a doença como um 'ser' e colocar como objetivo prioritário da medicina a eliminação desse 'ser' na busca do 'homem'. No caso da dor crônica a retirada desse 'ser' não somente é impossível como pode levar a não reconhecer o que está embaixo, caso o clínico não seja capaz de ouvir uma outra linguagem.

Essas mobilizações na biomedicina sobre a dor e suas conseqüências são reconhecidas, com maior ou menor entusiasmo, por autores do campo das ciências sociais. Há posições mais otimistas que as reconhecem como "uma espécie de giro copérnico dentro da medicina", ao retirar a dor da posição de satélite da enfermidade e reposicioná-la no centro, passando a enfermidade a girar em torno dela (Morris, 1996, p.85). Mas também há posições menos otimistas, que apesar de reconhecerem o avanço oferecido por esse movimento para a neurofisiologia, posicionam-se mais cautelosamente, considerando-o um "materialismo mais sofisticado" (Kirmayer, 1988, p.57).

Admitir a dor como fenômeno subjetivo e multidimensional, delinear uma teoria neurofisiológica que busca explicar essa complexidade com base na teoria dos sistemas, que inclui corpo-mente-sociedade-cultura e que retira do corpo e da biologia sua origem prioritária e principal explicação, não é suficiente para superar o paradigma biomédico na produção de conhecimento e na prática clínica, nem oferece, a priori, soluções em direção à constituição de um novo paradigma (Kuhn, 1975). As incertezas e fragilidades que a dor crônica expõe apenas fortalecem, para a biomedicina, o reconhecimento da teoria empiricista da linguagem (Good, 1994), do naturalismo e da separação corpo-mente como 'pano de fundo' (background) e reflexos de elementos constituintes profundos desse mundo, do qual a biomedicina origina-se e sobre o qual atua e produz sentido.

Concordamos com Lock e Gordon (1988), para os quais é impossível falar da biomedicina como uma medicina monolítica. Esta guarda heterogeneidades, reveladas tanto nas diferenças entre as especialidades médicas, como nas ambigüidades da prática clínica, em que o senso subjetivo dos praticantes predomina sobre qualquer que seja o fundamento objetivo, expresso através de incertezas e vulnerabilidades (Freidson, 1988, p.161). Esse lastro de conhecimentos tácitos produzidos e mobilizados no cotidiano da prática médica, mais do que sugerir alguma contradição ou desqualificá-la, oferece flexibilidade e vitalidade a essa medicina, no exercício de seu papel central para o Ocidente (Camargo Junior, 2003; Clavreul, 1983). 


\section{Os limites do naturalismo diante da dor crônica}

O naturalismo proposto por Charles Taylor (1985a, 1985b) corresponde à visão de que "os humanos são não somente uma parte da natureza, mas que esta natureza deve ser entendida de acordo com os cânones do Iluminismo", o que implica a rejeição da subjetividade e da positividade. Portanto a força do naturalismo e do paradigma das ciências naturais é devida ao fato de eles serem capazes "de obter um tipo de separação do nosso mundo pela sua objetivação" (Taylor, 1985, p.4) ).

Deborah Gordon (1988) sintetiza sete pressupostos básicos do naturalismo, que serão aqui apresentados em dois grupos. Os primeiros três pressupostos estão relacionados à epistemologia médica: a natureza é distinta do sobrenatural, a matéria é oposta ao espírito, portanto são substâncias distintas; a natureza é autônoma em relação à consciência humana, marcando a separação entre o objetivo e o subjetivo e entre a natureza e a experiência do indivíduo; a parte é independente e prioritária em relação ao todo - o atomismo -, admitindo-se em conseqüência que não só o todo é determinado pelas partes, como estas podem ser removidas de seu contexto sem alterar sua identidade. Os outros quatro pressupostos são decorrentes dos primeiros e mostram a relação entre natureza e sociedade: a natureza é independente e prioritária à cultura, portanto "símbolos/linguagem/representações retratam uma realidade empírica independente, mais do que a constituem" (Gordon, 1988, p.27); a natureza é separada dos valores humanos e da moralidade em geral, não cabendo julgamento de valor; a natureza é autônoma em relação à sociedade ("o que é natural é"), apesar da influência da esfera social; e a natureza como verdade é universal e autônoma do tempo e espaço.

Aplicados à medicina, esses pressupostos permitem compreender algumas implicações do naturalismo sobre as noções de corpo e doença na biomedicina. Ajudam também a reconhecer as dificuldades no campo da dor crônica como obliterações enraizadas nesses elementos constituintes e, portanto, intangíveis aos seus praticantes. A enfermidade real corresponde ao grau em que traços físicos são apresentados no corpo; os sinais objetivos são prioritários em relação aos sintomas ou queixas do paciente, para o desvendar da doença; portanto a doença (disease) é diferente da experiência do doente (illness) e tem prioridade sobre ela.

A medicina positiva valoriza os dados objetivos e nega a emoção, considerando-a um idioma inadequado para compreender a natureza. Mais que isso, a subjetividade do paciente é considerada disfuncional e suspeita (Clavreul, 1983; Lock, Gordon, 1988; Kirmayer, 1988). Apesar das recentes tentativas de valorização da subjetividade, a exemplo (emblemático) da clínica de dor, essa perspectiva encontra obstáculos na produção de conhecimento, tornandose afirmativa constante porém sem conseqüências epistemológicas. Na prática clínica permanece incompreensível ao clínico, ou indica apenas a hora de encaminhar o paciente para o psicólogo ou psiquiatra.

O reducionismo biológico no naturalismo admite que, uma vez que o mundo é composto de vários estratos de complexidade e, em todos eles, a natureza do ser é basicamente a mesma, "os diferentes níveis não são incomensuráveis, mas sim redutíveis" (Gordon, 1988, p.27)). Tal pressuposto sustenta e impulsiona a busca incansável pelo lócus da dor crônica, pela identificação da alteração primordial no corpo, nas estruturas ultramicro-elementares e complexas, o ponto para onde será direcionada a ação terapêutica, provavelmente 
medicamentosa - esta é a direção da maior parte dos investimentos de pesquisa na neurofisiologia da dor.

As conseqüências dos pressupostos que tratam da relação entre natureza e sociedade são ainda mais contundentes ao se refletirem na proposição atual do cuidado da dor crônica. Exploramos, neste artigo, apenas a distinção entre natureza e cultura, que admite não somente que a natureza ergue-se independentemente da cultura como é prioritária a ela, sendo a taxonomia médica um espelho da natureza real das doenças. Nesse sentido, a distinção entre o homem-natural e o homem-cultural permite considerar que, sob a parte humana (mente e espírito), onde se localiza também a cultura, está o homem-natural e os diversos níveis da anatomia, fisiologia e bioquímica. Logo, nessa última dimensão todo homem é essencialmente o mesmo (Gordon, 1988).

É farta a literatura que contradiz esse pressuposto com base no estudo da dor. A percepção e expressão da dor são francamente reconhecidas como moduladas pela cultura, sendo essa uma linha de pesquisa clássica da antropologia (Helman, 1995, Kirmayer, 2007). Um dos mais reconhecidos autores dessa linha, Zborowski (1952), salienta o papel das expectativas culturais e a aceitação da dor como parte da vida normal, por serem determinantes para a busca do cuidado médico. Ele discute o processo de educação infantil, a influência do contexto familiar, a atitude dos pais e demais participantes da rede de suporte da criança como elementos que orientam a formação de condutas e expectativas em relação à dor na idade adulta. Estuda também as diferenças do processo de tornar pública a dor, por meio de um elenco de comportamentos e atitudes frente à dor por parte indivíduos de diferentes origens étnicas. Atualmente essa perspectiva, embora seja reconhecida sua contribuição, por iniciar o estudo da dor baseado nas comparações culturais, tem sido muito questionada e apontada como reducionista porque valoriza a noção de estereótipos culturais, mais próximos de caricaturas do que de pessoas reais - um determinismo cultural que não explora outras particularidades como gênero e situação social e, de certa forma, faz uma leitura desumanizada da dor (Kleinman et al., 1994).

\section{O dualismo corpo-mente e a dor crônica}

O dualismo corpo-mente, para a biomedicina, está pautado na proposição filosófica de René Descartes, para quem corpo e alma são substâncias de essências distintas e cada uma segue suas leis próprias, sem comunicação, estabelecendo algum grau de relação por meio do contato direto (mecânico) na glândula pineal (Descartes, 1987; Chauí, 1995). Ao refletir sobre os limites desse pressuposto na prática com dor crônica, convém considerar a advertência de Dossey (1984, p.15), de que não se deve subestimar a força do dualismo cartesiano na medicina atual. Ele lembra que, a despeito do crescente descontentamento que possa existir com as abordagens tradicionais de saúde, a filosofia dualista mantém-se como a principal referência da medicina ocidental.

O desafio da dor vai além da superação da dicotomia 'dor real ou irreal', por ser ou não visível ao olhar médico (Rhodes et al., 1999). Apesar de haver conflitos para operar essa idéia na prática clínica, com base numa proposta teórica, a biomedicina dos últimos cinqüenta anos tem oferecido avanços que tentam superar essa questão, até porque, independentemente de sua realidade para a medicina, a dor é bem real para quem a sofre, e sendo o médico a 
autoridade máxima para o exercício do cuidado, não poderá negar-se a ouvir e frustrar-se com a sua impotência diante da dor. Portanto para a dor crônica está colocada a 'inevitabilidade' (Hilbert, Apr. 1984; Kotarba, July-Aug. 1981) e a frustração de todos em seu entorno.

A necessidade de repensar a relação corpo-mente, corpo-alma, superando a perspectiva dicotômica, remete a questões filosóficas com conseqüências não previsíveis sobre o que hoje entendemos como biomedicina. $\mathrm{O}$ leque de proposições que tenta repensar essas relações na clínica de dor é amplo e requer atenção, no mínimo para identificar se pontes estão sendo construídas ou se, apesar da intenção, o foco continua sendo no indivíduo, no pragmatismo e na funcionalidade. A insuficiência das abordagens psicossomáticas para superar o dualismo corpo-mente é apontada, por reproduzirem elas os mesmos valores da biomedicina, com o restabelecimento da dominância e controle da mente sobre o corpo e da razão sobre a emoção, mantendo-se portanto, e até aprofundando, esse dualismo (Kirmayer, 1988).

Seguindo essa linha de pensamento, Laurence Kirmayer (1988) afirma que o problema da relação corpo-mente é essencialmente ético, uma vez que simboliza pólos contrastantes da experiência humana no Ocidente: o voluntário e o involuntário, o intencional e o acidental. O autor utiliza a teoria da metáfora para examinar como valores estão subjacentes na retórica da biomedicina ou da racionalidade científica. A enfermidade (sickness) é uma ameaça à racionalidade, portanto uma pessoa doente rompe com a racionalidade em vários pontos, desde o momento em que "recorda aos demais os limites da razão" (p.85), até, e mais gravemente, quando de alguma forma desobedece as determinações dessa razão, pela não adesão ao tratamento, pela recusa a submeter-se a determinado procedimento, ou ainda quando a resposta terapêutica não é a esperada, o que é freqüente na dor crônica. Esse é um tema polêmico que está sendo atualizado em discussões sobre o direito do doente ao esclarecimento e à escolha das intervenções diagnóstico-terapêuticas, especialmente para a medicina norteamericana (Armstrong, 1984; Csordas, 1994; Murphy, 1990.

Essas polarizações trazem como conseqüência imediata a ordem moral através da responsabilidade, como um problema de grau de consciência, intenção ou voluntariedade da ação, e sua decorrência, que é a culpabilização do doente pela doença. A ampla discussão sobre o comportamento doloroso, os ganhos primário, secundário e terciário ${ }^{7}$ no campo do tratamento da dor crônica sinalizam a necessária reflexão sobre essa questão, ao pensar as conseqüências práticas para a vida do doente e do médico para além da relação terapêutica, no campo da responsabilidade jurídica. Para Kirmayer (1988) tais valores expõem a seguinte questão: "Pacientes são racionais, mas moralmente suspeitos na escolha de ser doente, ou irracionais e, portanto, moralmente inocentes, mas mentalmente incompetentes" (p.83).

Na dor crônica a relação corpo-mente está permanentemente presente, pois envolve esses dois domínios, sem estar exclusivamente em um dos dois. A objetivação e a subjetivação da dor, nesse caso, confundem-se com o reconhecimento de si mesmo como sendo dor, 'a dor sou eu', em contraste com a não-aceitação dessa condição: “Não; eu não vou me aceitar deste jeito. Eu vou me querer melhor" (Jackson, 2000, p.143). Essas falas, de pacientes de um Centro Multidisciplinar de Dor entrevistados por Jackson (2000), retratam experiências semelhantes e cotidianas nas clínicas de dor.

A tentativa de objetivação da dor normalmente é pelo caminho da busca incessante de um diagnóstico, por meio de exames e testes dos mais diversos, muitas vezes invasivos, infringindo 
dor. A busca de um nome, de uma identidade para a dor, que a torne passível de ser localizada no corpo, apresentada aos outros e em perspectiva retirada, é, talvez, a característica mais marcante desses doentes (Good, 1994; Jackson, 2000). O maior risco desse processo é os doentes submeterem-se a tratamentos ineficazes e muitas vezes iatrogênicos.

No outro extremo, a subjetivação da dor leva à sua identificação com a essência do ser, o self. Um corpo cheio de dor confunde-se com o self integrando uma só dimensão. Portanto dor crônica não pode ser entendida apenas 'através' dessas duas dimensões; antes, ela 'é' radicalmente a expressão dessas dimensões, o 'eu e não-eu' (me and not-me) como propõe Jackson (2000). Essa penetração e permanência modificam o em-si e o em-torno, alterando a referência de corpo, tempo e espaço. O corpo passa a personificar um agente agressivo que age contra o self; o tempo é distorcido e perde seu poder de ordem. Como descreve brilhantemente Good (1994): "Espaço e tempo são sobrecarregados de dor, e o mundo privado não somente perde sua relação com o mundo em que os outros vivem, como suas dimensões muito organizadas começam a sucumbir. A dor ameaça desfazer o mundo e no retorno subverte o self" (p.126).

Pensar a terapêutica como algo com tamanha complexidade implica ver de um outro modo e falar uma outra linguagem. Talvez tal aproximação com a dor crônica inspire a necessidade de repensar a ordem das 'palavras e das coisas', novamente como sugerem Byron Good e Mary-Jo Delvecchio Good (1980) em referência a Foucault, tratando do modelo hermenêutico. A idéia de holograma, o paradigma da complexidade e o exercício da transdisciplinaridade trazem a não-linearidade, a não-dualidade, a não-separação sujeito-objeto e, ao mesmo tempo, admite que a ação integrada em um ponto tem a potencialidade de modificar toda a imagem. Edgar Morin (1998) propõe o paradigma da complexidade com base no exercício da transdisciplinaridade, por reconhecer que os objetos complexos têm como característica o que chama de triplo enraizamento em grandes domínios: da física, da biologia e da antropossociologia. Para estabelecer comunicação em circuito entre eles, sugere, com base numa construção teórica instigante, um movimento de enraizamentos simultâneos e complementares, do antropossocial no biológico, do biológico na physis, e desta no social e também no antropológico (Morin, 1998, 1999; Morin, Moigne, 2000).

\section{Reconstruindo caminhos baseados na prática}

Em estudo sobre centros de dor na Holanda, Mariet Vrancken (1989) identifica cinco escolas ou abordagens da dor crônica, com base em entrevistas com médicos e psicólogos em oito centros de dor. O material foi tratado com base na ground theory, depreendendo caminhos predominantes sobre a compreensão da dor e da dor crônica para os terapeutas. Tal detalhamento é importante, pois, para os fins deste artigo, essa construção produzida por Mariet Vrancken (1989) será lida também como 'tipos ideais' na perspectiva weberiana.

A primeira dessas escolas seria a que é sustentada mais diretamente pela chamada Teoria de Comporta e suas decorrências diretas. Vrancken reconhece que essa escola de pensamento é marcadamente dualista, orientada pelo corpo, focalizada no funcionamento do sistema nervoso e da transmissão nervosa, e assume a dor crônica como fenômeno psicobiológico. Há também ênfase na patologia física como um elemento necessário, e os demais fatores são vistos como contribuintes para a expressão final da dor. 
As outras quatro escolas foram denominadas somato-técnica, behaviorista, fenomenológica e abordagem da consciência (consciousness approach). A abordagem somato-técnica é orientada por uma perspectiva pragmática, na qual dor é essencialmente orgânica, e a única distinção entre dor aguda e crônica é o fator tempo. Essa abordagem é coincidente com o que Isabelle Baszanger (1992), outra autora interessada nesse tema, denomina cura pela tecnologia. Para essa escola existem três tipos de pacientes: pacientes com dor real, os psiquiátricos e os simuladores. Após diagnóstico criterioso das causas físicas e intervenção adequada, a permanência da dor remete o paciente às duas últimas classificações.

Para a escola comportamental (behaviorista) a dor é aprendida, e fatores ambientais e pessoais compõem o papel principal na gênese da síndrome dolorosa crônica, que deverá ser preferencialmente tratada pelo psicólogo. Seria, para Baszanger (1992), a cura pela adaptação. O paciente ideal, nesse caso, é aquele que pode ser convencido de que sua dor é decorrente de uma situação particular e mostra-se cooperativo com a terapêutica, cujo objetivo principal é minimizar o 'comportamento doloroso' e fazer o paciente readquirir o controle sobre sua própria vida. A reabilitação e ressocialização do paciente ocorrem à medida que ele redireciona o foco de sua atenção para outros domínios da vida que não o físico, aprenda a prevenir os episódios de agudização e, portanto, reduza o uso de medicação analgésica, os dias parados e a procura contínua por cuidado médico.

As duas outras abordagens, a fenomenológica e a da consciência (consciousness approach), possuem perspectivas mais arrojadas do que outras experiências descritas na literatura (Morris, 1996; Bendelow, Williams, 1995; Csordas, 1994; Jackson, 2000), mas anunciam caminhos sem dúvida instigantes para o interesse deste estudo. Para a abordagem fenomenológica, a dor é um 'modo-de-ser-no-mundo', em que o corpo torna-se o centro da vida-no-mundo (Lebenswelt). O sentido de 'evento doloroso', como iniciador do processo, ganha papel decisivo na ocorrência da dor, pois é compreendido como um colapso e uma distorção da função fisiológica da dor (Vrancken, 1989, p.438), deixando o sofredor de ser uma 'pessoa' para ser um 'paciente'. O objetivo dessa terapia é reintegrá-lo à vida. O caminho para isso é a compreensão do sentido da dor, partilhada pelo doente, o terapeuta e os parceiros (familiares) com base numa abordagem autobiográfica. O papel do terapeuta é silenciar e ouvir, priorizando o encontro clínico como condição de possibilidade para esse 'retorno'. Desse modo, o terapeuta considera que o paciente, à medida que reconstrói sua historicidade, resgata e redescobre sua capacidade de restaurar a saúde independentemente do médico. Finalmente, a abordagem da consciência admite que a dor crônica é um problema da restrição da consciência, que é direcionada para uma parte específica do corpo, a qual passa a ser totalmente preenchida pela dor. Despertar a consciência inclui a habilidade de refletir sobre o selfe ganhar autoconsciência como um mecanismo para torná-lo 'livre'. A terapia estaria orientada para a relação interpessoal entre doente e terapeuta, e o papel deste seria o de guiar o doente (p.439-440).

Sem dúvida, essas duas últimas abordagens se complementam e revelam-se confluentes com o pensamento em construção neste artigo. No entanto ao refletir sobre esses tipos ideais no contexto da prática clínica surge a questão: a que terapeuta se refere a proposta, um psicólogo treinado no tratamento da dor, ou um médico clínico treinado na escuta psicológica? Cabe lembrar que, em nosso contexto cultural, alguém com dor provavelmente procuraria um médico e não um psicólogo. E mesmo que fosse procurado, o psicólogo tenderia a encaminhar 
o paciente ao médico, para dar suporte à avaliação e ao acompanhamento da dimensão física da dor. Podemos dizer que, a par do que Byron Good (1994) chamou de princípios formativos da biomedicina, o olhar, o escrever e o falar, a dor crônica requer a valorização do escutar, compreender e negociar, se não como princípios formativos, ao menos como recursos mobilizados pela prática clínica para a viabilização do encontro clínico. E ainda teremos de reconhecer que a viabilização do projeto terapêutico da clínica de dor só é possível em equipe.

\section{Por uma perspectiva compreensiva da dor: brechas como aberturas ${ }^{8}$, crise como possibilidade}

Por um lado, a dor crônica, objeto insubordinado que escapa em muitos sentidos ao paradigma biomédico, transgride os backgrounds da racionalidade empiricista e cria situações ameaçadoras dos saberes e das práticas da arena profissional no cuidado da saúde. Por outro, abre oportunidades para repensar e refazer, de muitas maneiras, os caminhos. Mais do que isso, redimensiona a incerteza de todos os envolvidos, exigindo a mobilização de recursos adormecidos, a exploração de perspectivas não consideradas e a ação e o compromisso com base numa interação democrática (Ayres, 2001).

A dor crônica não é apenas um problema de transmissão nervosa, neurotransmissores, canais de sódio, ou qualquer outra ultra-micro-estrutura que se possa encontrar. Render-se a tal constatação é um passo inicial para começar o diálogo. A dor crônica é simultaneamente física e emocional, biológica e fenomenologicamente incorporada; é experiência e expressão, uma linguagem situada num contexto sociocultural. Ou seja, a dor crônica é intersubjetiva (Bendelow, Williams, 1995; Kleinman et al., 1994). Pensar o cuidado para esse panorama requer repensar referências teóricas, novas práticas e novos praticantes a serem formados, baseando-se num outro ponto de vista.

A primeira aproximação a ser feita é com a tradição da fenomenologia do corpo ou embodiment. O corpo, para a fenomenologia, é um estar-no-mundo, lançado a um projeto por inteiro. Como descreve Merleau-Ponty (1999, p.205), "ser corpo ... é estar atado a um certo mundo, e nosso corpo não está primeiramente no espaço: ele é no espaço". A dor crônica, por esse ponto de vista, pode ser definida como um certo modo-de-ser-no-mundo, resultado do movimento da existência quando eventos fisiológicos e psicológicos não são mais distinguíveis respectivamente como a ordem do em-si e do 'para-si; ambos estão dirigem-se ao pólo intencional ou em direção ao mundo (Honkasalo, Apr. 2000, p.198).

Nessa mesma linha, mas numa outra perspectiva, Leder (1990) traz o aspecto da 'ausência do corpo' ou da transparência do corpo (Bourdieu, 2001) como algo que pode ser rompido na presença da dor, da doença e da morte. Em outras palavras, em contraste com a transparência que caracteriza o corpo em seu funcionamento ordinário, no contexto da dor, sofrimento e morte o corpo reaparece de forma disfuncional e torna-se o foco da atenção (Bendelow, Williams, 1995).

Reconhecer esse pólo da experiência da dor, o do sofredor, requer também ponderar sobre um outro pólo, o da experiência do terapeuta, que traz em si um processo de aquisição de conhecimento e tecnologia por meio de uma experiência que é resultado não só de um processo cognitivo massivo, mas de um modo de ver o mundo. Como descreve a estudante de medicina 
entrevistada por Byron Good (1994), "sinto como se eu estivesse mudando meu cérebro todos os dias, moldando-o num modo específico - um modo muito específico" (p.65). Esse "modo específico' significa um aprendizado sobre a construção do mundo médico como "uma forma distinta da realidade, por aqueles que estão aprendendo a ser médicos" (p.65).

Good (1994) utiliza a teoria do filósofo idealista Ern Cassirer sobre formas simbólicas, como ponto de partida para a análise dos princípios formativos específicos da clínica médica contemporânea, admitindo que essas formas constituem diferentes 'imagens de mundo', que não somente refletem o dado empiricamente mas também produzem o mundo em concordância com um princípio independente ( p.68). O autor afirma que essa medicina não é apenas um discurso, e posicionando-se diferentemente de Foucault reconhece, de um ponto de vista antropológico, o papel do sujeito, a centralidade da experiência e as qualidades dialógicas e intersubjetivas do discurso.

Neste ponto vale lembrar a discussão de Mary-Delvecchio Good (Apr. 1989) sobre a formação médica. Partindo da inabilitação dos praticantes devido a distorções da escola médica americana, alerta para a necessidade de os estudantes lidarem bem com a polaridade competência/cuidado, sendo a primeira relacionada à linguagem das ciências básicas, do conhecimento cognitivo e da habilidade técnica e a segunda expressa na linguagem das relações, atitudes, compaixão e empatia. Trata-se este último de um pólo não-técnico, que envolve os recursos pessoais do médico. Sem dúvida que o pólo da competência tem se tornado cada vez mais importante nos Estados Unidos, o que não é essencialmente diferente nos demais países ocidentais. No entanto, para a autora, a questão não é apenas cultivar atitudes, mas repensar globalmente a formação médica incorporando as ciências sociais e, portanto, reconfigurando o discurso da medicina, mais do que reproduzindo a polaridade colocada.

Para Kirmayer (1988), as mudanças mais substantivas do treinamento médico envolvem questões que ultrapassam o aprendizado de lidar com a emoção e a introdução de novos conteúdos no currículo da escola médica. O autor defende que transcender o dualismo corpomente e expandir o papel da emoção e do relacionamento na formação médica envolvem uma troca entre a preocupação com as causas e a ênfase no cuidado e, ainda, implica "mudanças significativas na atmosfera competitiva, individualista e racionalista da sala de aula e a rígida hierarquia de aprendizagem, na qual a dominação do estudante pelo professor reproduz a dominação do paciente pelo médico" (p.84).

As alternativas construídas pela biomedicina para tratar a dor crônica constituem espaços singulares para a investigação das ciências sociais em inúmeras direções, algumas delas trazidas aqui por serem de maior interesse nosso: o estudo dos sentidos produzidos e mobilizados entre profissionais de saúde, no relacionamento entre si e com os doentes, que permite explorar os recursos utilizados para estabelecer aproximações e superar as limitações postas à técnica diante do sofrimento; a investigação da dinâmica operada no interior do espaço terapêutico, reconhecendo polaridades e alternativas criadas entre saberes e práticas para implementação de um sistema terapêutico; e o estudo do processo de formação terapêutica, a partir das trajetórias profissionais, certezas e vulnerabilidades, descobertas e mudanças diante da experiência da inevitabilidade, da impotência e do fracasso ao lidar com pessoas envolvidas com a dor crônica.

Os aportes teórico-metodológicos considerados para tal empreendimento têm afinidade com o programa de pesquisa de Byron Good, no contexto mais amplo da psiquiatria 
transcultural e da antropologia interpretativa. A rede de semântica e os modelos clínicos presentes no cotidiano da clínica são pensados por Good e Good (1980) como recursos para a construção de uma abordagem centrada no sentido (meaning centered approach), a ser utilizada como meio de reorientação das transações clínicas. A abordagem permite a tradução de achados das ciências sociais em modelos que podem ser usados pelos clínicos e ensinados na escola médica. Essa perspectiva, apontada por Byron Good (1994), visa à aproximação entre o modelo clínico biomédico e o modelo clínico hermenêutico, não apenas como forma de facilitação da relação médico-paciente ou para decodificação e tradução das queixas do paciente e evidências observadas em nomes de doenças (Felnstein, 1973, citado em Good, Good, 1980), mas como objeto de reflexão e formação de terapeutas.

O estudo das redes de perspectivas tem resultado refinado do trabalho de Good (1994), quando ele aproxima a complexidade da doença ao objeto estético, em referência a Wolfgang Iser. Permite refletir sobre a constituição da enfermidade (illness) na experiência pessoal e como objeto da atenção médica e social, com base na condução de múltiplas sínteses, reunindo memória e antecipação mediadas por um ponto de vista em movimento (moving viewpoint). Para Wolfgang Iser, "o objeto estético é uma forma particularmente complexa e dinâmica entre performance e audiência (texto e leitor), uma relação que depende e transcende ambos performance e audiência, texto e leitor, o objeto material e uma reflexão sensorial" (Good, 1994, p.166). Iser (1999, p.12), propõe que, "por um lado o texto é apenas uma partitura e por outro, são as capacidades dos leitores, individualmente diferenciados, que instrumentam a obra".

Essa abordagem pode ser enriquecida pelo estudo da heteroglossia e da polivocalidade das práticas interpretativas, formas de conhecimento e instância moral dos diversos atores envolvidos (Silva, 2003). Com tal orientação teórica, a compreensão da dor como objeto de intervenção de diferentes abordagens terapêuticas - estando o doente não só integrado ao projeto terapêutico, mas também no centro do trabalho médico (Baszanger, 1989) - requer a compreensão dos discursos e das relações dialógicas entre terapeuta-terapeuta e terapeutadoente, admitindo-se "o permanente diálogo, nem sempre simétrico e harmonioso" (p.96), e a dialética que "se estabelece entre o eu e o outro nos processos discursivos instaurados historicamente pelos sujeitos", reconhecendo-se assim a permanência do caráter polifônico da relação pela linguagem (Brait, 1997, p.101)

\section{NOTAS}

${ }^{1}$ A ciência normal consiste em solucionar quebra-cabeças, mas ao mesmo tempo deverá ser eficaz para induzir mudanças nesses mesmos paradigmas que a orientam. "A descoberta começa com a consciência da anomalia, isto é, com o reconhecimento de que, de alguma maneira, a natureza violou as expectativas paradigmáticas que governam a ciência normal" (Kuhn, 1975, p.77).

${ }^{2}$ Castro (1999) assinala que foram levantados setenta serviços de tratamento da dor em todo o Brasil até 1998, implantados progressivamente a partir da década de 1960, tendo o maior impulso ocorrido a partir dos primeiros anos das décadas de 1980 e 1990. A grande maioria desses serviços e centros formadores está localizada na região Sudeste: 38 unidades (54\%), sendo 17 (24\%) em São Paulo. No Nordeste foram registrados 13 (18\%) serviços, sendo dois na Bahia. A classificação desses serviços segundo os critérios da 
Iasp mostra que 39 (55\%) deles estão no tipo quatro, denotando uma fase ainda inicial, com menor estruturação quanto a protocolos de atendimento e avaliação do tratamento oferecido.

${ }^{3}$ A categoria 'racionalidade médica' é utilizada aqui conforme proposta por Madel Luz (1996, p.5), “ao estilo de um tipo ideal, isto é, com seus traços ou dimensões fundamentais modelados a partir de uma operação indutiva. Tal operação constata num objeto específico de categorização a presença, com maior ou menor grau de explicitação e clareza, daqueles traços ou dimensões fundamentais". É como um modelo tendencial histórico, "que nunca chega a se realizar de forma acabada, pois, tem a capacidade de ser modificado historicamente pela ação dos atores sociais. Esta forma de visão tendencialista do conceito, enraizada na história, elimina, a nosso ver, os efeitos apriorísticos da definição em termos de modelos ideais" (p.5).

${ }^{4}$ O papel do CPME tem sido valorizado no estudo da dor, por ser considerado importante local de conexão entre os diversos níveis do sistema nervoso central. Essa formulação tem repercussões significativas no projeto terapêutico.

${ }^{5}$ Causalgia é a dor severa e em queimação, que pode resultar de lesão parcial do sistema nervoso periférico; dor fantasma é a permanência de dor após a amputação do membro afetado; e neuropatia periférica é a dor que ocorre após infecção do nervo periférico, como a neuropatia do trigêmeo ou em casos de doença degenerativa.

${ }^{6}$ Tradução livre, nesta e nas demais citações de obras editadas em outros idiomas.

${ }^{7}$ Bokan, Ries e Katon (1981, citados em Csordas, 1994, p.224) definem ganho primário como "mecanismo intrapessoal, psicológico para a redução dos afetos inaceitáveis ou conflitos e o ganho secundário como a vantagem interpessoal ou ambiental suprida pelo sintoma; e o ganho terciário envolve alguém que, mais do que o paciente, busca obter ganhos a partir da enfermidade de um paciente".

${ }^{8}$ O campo semântico da palavra 'brecha' oferece um amplo leque de sentidos. Neste texto, essa palavra é usada no sentido de lacuna, fenda, espaço vazio; ferida larga e profunda (Encyclopédia Britannica do Brasil Publicações, 1990). Conforme o dicionário Aurélio, brecha origina-se do francês brêch, e entre os muitos usos, especialmente na geologia, brecha pode referir-se a "estar sempre pronto para a luta, ou estar em vias". Já a palavra 'abertura é aqui entendida como ação de abrir; disposição para entendimentos, permissividade - nesta acepção, antônimo de radicalidade, intolerância (Encyclopédia Britannica do Brasil, 1990).

\section{REFERÊNCIAS BIBLIOGRÁFICAS}

ARMSTRONG, David

The patient view. Social Science of Medicine, Oxford, v.18, n.9, p.737-744. 1984

AYRES, José Ricardo C.M.

Sujeito, intersubjetividade e práticas de saúde.

Ciência e Saúde Coletiva, Rio de Janeiro, v.6, n.1, p.63-72. 2001

BASZANGER, Isabelle

Deciphering chronic pain. Sociology of Health and Illness, Henley on Thames, v.14, n.2, p.181215. 1992

BASZANGER, Isabelle

Pain: its experience and treatment. Social Science of Medicine, Oxford, v.29, n.3, p.425-434. 1989

BENDELOW, Gillian A.; WILLIAMS, Simon J. Transcending the dualism: towards a sociology of pain. Sociology of Health and Illness, Henley on Thames, v.17, n.2, p.139-165. 1995
BERKER, Niels et al.

Treatment outcome of chronic non-malignant pain patients managed in a Danish multidisciplinary pain centre compared to general practice: a randomised controlled trial. Pain, Amsterdam, v.84, p.203-211. 2000

BLYTH, Fiona M. et al.

Chronic pain in Australia: a prevalence study. Pain, Amsterdam, v.89, p.127-134. 2001

BOKAN, J.A., RIES, R.K., KATON, W.J. Tertiary gain and chronic pain. Pain, Amsterdam, v.10, p.331-335. 1981

BORCK, C.; HESS, V.; SCHMIDGEN, H. Re-assessing Canguilhem: pathological measurement in science, technology and medicine. Disponível em: http://vlp.mpiwgberlin.mpg.de/exp/schmidgen_e/ pathological_measurement.html. Acesso em: 26 fev. 2008. 2001 
BOURDIEU, Pierre

Meditações pascalianas. Rio de Janeiro: Bertrand Brasil. 2001

BRAIT, Beth

Bakhtin, dialogismo e construção do sentido. Campinas: Ed. Unicamp. 1997

CAMARGO JUNIOR, Kenneth Rochel de Biomedicina, saber e ciência: uma abordagem crítica. São Paulo: Hucitec. 2003

\section{CANGUILHEM, George}

O normal e o patológico. Rio de Janeiro:

Forense-Universitária. 1982

CASTRO, Antônio B.

Tratamento da dor no Brasil: evolução histórica. Curitiba: Ed. Maio. 1999

CHAUÍ, Marilena

Espinosa: uma filosofia da liberdade. São Paulo: Moderna. 1995

CLAVREUL, Jean

A ordem médica: poder e impotência do discurso médico. São Paulo: Brasiliense. 1983

COHEN, Mitchell J.M.; CAMPBELL, James N. Pain treatment centers at a crossroads: a practical and conceptual reappraisal. Seattle: Iasp Press. 1996

CSORDAS, Thomas J. (Ed.)

Embodiment and experience: the existential ground of culture and self. Cambridge: Cambridge University Press. 1994

DESCARTES, René

As paixões da alma. In: Descartes. São Paulo: Abril Cultural. p.217-237. (Col. Os Pensadores). 1987

DOSSEY, Larry

Beyond illness. Boulder: New Science Library. 1984

ELIOT, Alison M. et al.

The epidemiology of chronic pain in the comunity. The Lancet, London, v.354, p.12481252. Oct. 1999

FELNSTEIN, Alvan R.

An analisys of diagnostic reasoning. Yale Journal of Biology and Medicine, New Haven, n.46, p.212-232; 264-283. 1973

FOUCAULT, Michel

O nascimento da clínica. Rio de Janeiro: ForenseUniversitária. 1977

\section{FREIDSON, Eliot}

Profession of medicine: a study of the sociology of applied knowledge. Chicago: The University of Chicago Press. 1988

GOOD, Byron

Medicine, rationality, and experience: an

anthropological perspective. Cambridge: Lewis
Henry Morgan Lectures; Cambridge University Press. 1994

GOOD, Byron; GOOD, Mary-Jo Delvecchio The meaning of symptoms a cultural hermeneutic model for clinical practice. In: Eisenberg Leon; Kleinman, Arthur (Ed.). The relevance of social science for medicine. Dordrecht: Reidel Publishing Company. p.165-196. 1980

GOOD, Mary-Jo Delvecchio

Disabling practitioners: hazards of learning to be a doctor in american medical education. American Journal of Orthopsychiatry, New York, v.59, n.2, p.303-309. Apr. 1989

GORDON, Debora R.

The assumption in Western medicine. In: Lock, Margaret; Gordon, Deborah R. (Ed.). Biomedicine examined. Dordrecht: Kluwer Academic Publishers. p.19-56. 1988

HASSELSTROM, Jan; LIU-PALMGRENB, Jenny; RASJO-WRAAKR, Gorel

Prevalence of pain in general practice. European Journal of Pain, London, v.6, n.5, p.375-385.

Oct. 2002

HELMAN, Cecil

Cultura, saúde e doença. Porto Alegre: Artes Médicas. 1995

HILBERT, Richard A.

The acultural dimensions of chronic pain: flawed reality construction and the problem of meaning. Social Problems, v.31, n.4, p.365-378. Apr. 1984

HONKASALO, Maria-Liisa

Chronic pain as postures towards the word.

Scandinavian Psychology Association, v.41, p.197-208. Apr. 2000

\section{IZER, Wolfgang}

O ato da leitura: uma teoria do efeito estético. v.2. Trad. Johannes Kretschmer. São Paulo: Ed. 34. 1999

JACKSON, Jean E.

"Camp pain": talking with chronic pain patients. Philadelphia: University of Pennsylvania Press. 2000

JACKSON, Jean E.

Chronic pain and the tension between the body as subject and object. In: Csordas, Thomas J. (Ed.). Embodiment and experience: the existential ground of culture and self. 9.ed. Cambridge: Cambridge University Press. p.201-228. 1994

KIRMAYER, Laurence J.

On cultural mediation of pain. In: Coakley, Sarah; Shelemay, Kay K. (Ed.). Pain and its transformations: the interface of biology and culture. Cambridge: Harvard University Press. p.363-401. 2007 
KIRMAYER, Laurence J.

Mind and body as metaphors: hidden values in biomedicine. In: Lock, Margaret; Gordon, Deborah R. (Ed.). Biomedicine examined. Dordrecht: Kluwer Academic Publishers. p.57-93. 1988

KLEINMAN, Arthur et al.

Pain as human experience. Berkeley: University of California Press. 1994

KOTARBA, Joseph A.

Chronic pain center. A study of voluntary client. Compliance and entrepreneuship. American Behavorist Scientist, v.24, n.6, p.786-800. July-Aug. 1981

KUHN, Thomas

A estrutura da revolução. São Paulo: Perspectiva. 1975

LEDER, Drew

Clinical interpretation: the hermeneutics of medicine. Theoretical Medicine, Dordrecht, n.11, p.9-24. 1990

LOCK, Margaret; GORDON, Deborah

Biomedicine examined. Dordrecht: Kluwer Academic Plublishers. 1988

LUZ, Madel Terezinha

V Seminário do Projeto Racionalidades Médicas. Rio de Janeiro: Ed. Uerj. (Série Estudos em Saúde Coletiva, 136). 1996

LUZ, Madel Therezinha

Racionalidades médicas e terapêuticas alternativas.

Rio de Janeiro: Ed. Uerj. (Série Estudos em Saúde Coletiva, 62). 1993

\section{MACHADO, Roberto}

Ciência e saber: a trajetória da arqueologia de Foucault. Rio de Janeiro: Graal. 1981

MELZACK, Ronald; WALL, Patrick D.

O desafio da dor. Lisboa: Fundação Calouste Gulbenkian. 1982

MELZACK, Ronald; WALL, Patrick D.

Pain mechanisms: anew theory. Science,

Washington, v.150, p.971-979. 1965

\section{MERLEAU-PONTY, Maurice}

Fenomenologia da percepção. São Paulo: Martins Fontes. 1999

\section{MORIN, Edgar}

Por uma reforma do pensamento. In: Pena-Veja, Alfredo; Nascimento, Elimar P. (Org.). O pensar complexo: Edgar Morin e a crise da modernidade. Rio de Janeiro: Garamond. p.21-34. 1999

MORIN, Edgar

Ciência com consciência. Rio de Janeiro: Bertrand Brasil. 1998
MORIN, Edgar; MOIGNE, Jean-Louis A inteligência da complexidade. São Paulo: Peirópolis. 2000

MORRIS, David

La cultura del dolor. Santiago de Chile: Andrés Bello. 1996

MURPHY, Robert Francis

The body silent: an anthropological embarks on the most challenging journey of his life - into the world of the disabled. New York: Norton Paperback. 1990

PIMENTA, Cibele A.M.

Atitudes de doentes com dor crônica frente à dor. Tese (Doutorado) - Escola de Enfermagem, Universidade de São Paulo, São Paulo. 1999

PIMENTA, Cibele A.M et al.

Epidemiologia da dor. In: Figueiró, João Augusto B.; Angelotti, Gildo; Pimenta, Cibele A.M.

(Org.). Dor \& saúde mental. Rio de Janeiro: Atheneu. 2005

RHODES, Lorna A. et al.

The power of the visible: the meaning of diagnostic tests in chronic back pain. Social Science of Medicine, Oxford, v.48, p.1189-1203. 1999

SILVA, Luis Augusto Vasconcelos Saúde e produção de sentidos no cotidiano: práticas de mediação e translingüística Bakhtiniana. Interface - Comunicação, Saúde, Educação, Botucatu, v.7, n.13, p.135-148. 2003

TAYLOR, Charles

Philosophical papers. v.1: human agency and language. Cambridge: Cambrigde University Press; 1985 a

TAYLOR, Charles

Philosophical papers. v.2: philosophy and the human sciences. Cambridge: Cambridge University Press. 1985b

TEIXEIRA, Manoel Jacobsen

Fisiopatologia da dor neuropática. Revista Médica, São Paulo, v.78, p.53-84. 1999

TEIXEIRA, Manoel Jacobsen et al. Dor no contexto interdisciplinar. Curitiba: Ed. Maio. 2003

VRANCKEN, Mariet A.E.

Schools of thought on pain. Social Science of Medicine, Oxford, v.29, n.3, p.435-444. 1989

ZBOROWSKi, Mark

Cultural components in responses to pain. Journal of Social Issues, Malden, v.8, p.16-30. 1952 


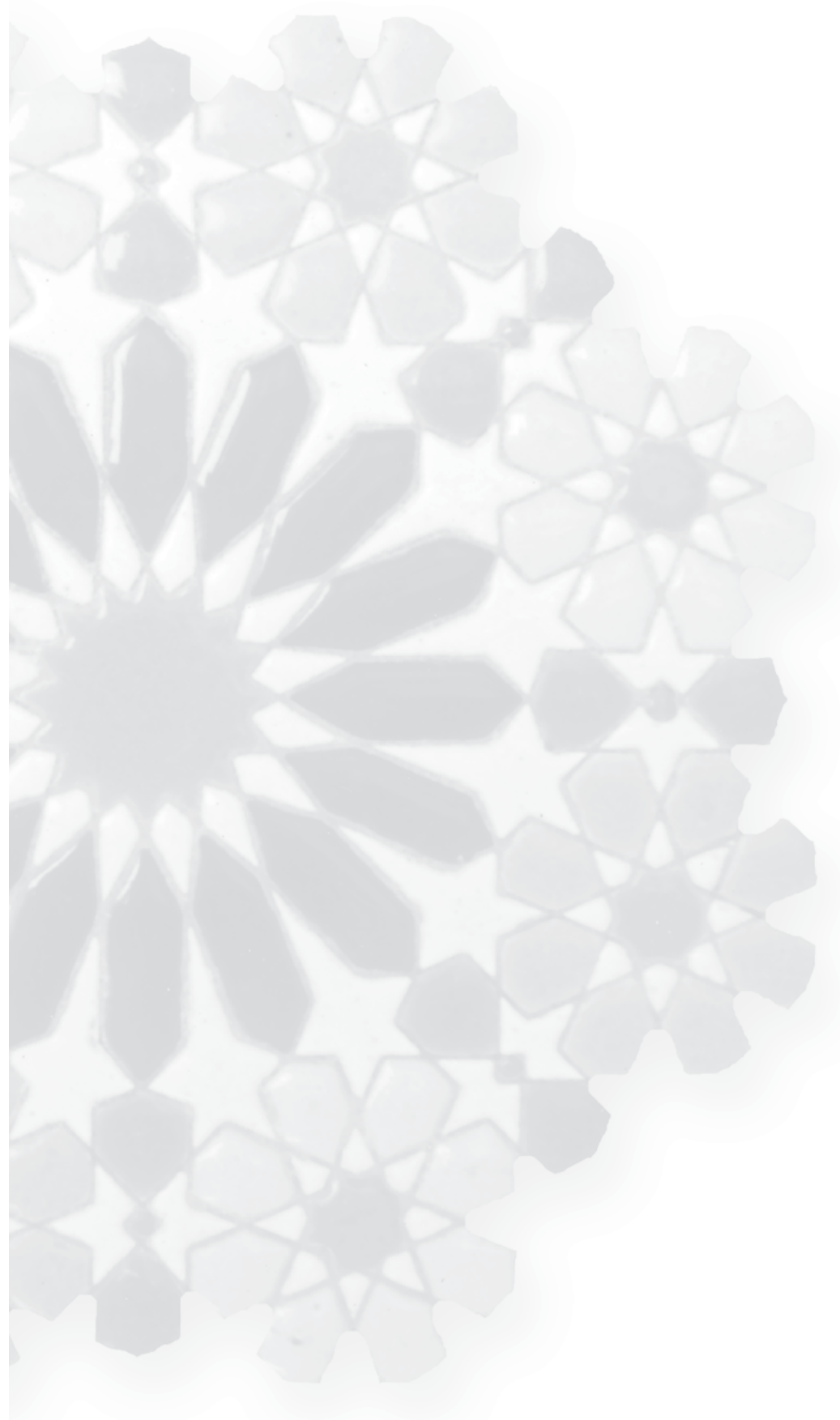

